\title{
IMPLEMENTASI INTERNET OF THINGS SEBAGAI MONITORING SUHU PADA PEMANGGANG OTOMATIS BERBASIS ARDUINO UNO
}

\author{
THE IMPLEMENTATION OF THE INTERNET OF THINGS \\ AS TEMPERATURE MONITORING IN AUTOMATIC ROASTERS \\ BASED ON ARDUINO UNO
}

\author{
Andreanus Calvin Hugo ${ }^{1}$, Rahmat Hidayat ${ }^{2}$, Lela Nurpulaela ${ }^{3}$ \\ ${ }^{1}$ Universitas Singaperbangsa Karawang \\ ${ }^{2}$ Universitas Singaperbangsa Karawang \\ ${ }^{3}$ Universitas Singaperbangsa Karawang \\ calvin.hugo16023@ student.unsika.ac.id, ${ }^{2}$ rahmat.hidayat@staff.unsika.ac.id, \\ 3lela.nurpulaela@ft.unsika.ac.id
}

\begin{abstract}
Abstrak
Internet of Things (IoT) adalah struktur dimana objek disediakan dengan identitas eksklusif dan kemampuan untuk pindah data melalui jaringan tanpa memerlukan dua arah seperti manusia ke manusia, sumber ke tujuan atau interaksi manusia ke komputer. IoT memungkinkan pengguna dan perangkat dapat terhubung kapan saja, dimana saja, dan dengan apa saja. Tujuan penelitian ini ialah untuk mengetahui cara kerja atau mekanisme dari Implemntasi IoT pada pemanggang otomatis berbasis Arduino Uno menggunakan sensor Thermocouple dan Sensor Api KY 026 sebagai inputnya. Berdasarkan hasil penelitian menunjukkan NodeMCU dapat terhubung dengan jarak 60 meter dari sumber dari sumber jaringan tanpa ada benda yang dapat menghalangi koneksi internet dan mengalami delay dibawah satu detik di jarak 35 meter.
\end{abstract}

Kata kunci : Internet of Things, Thermocouple, NodeMCU, Sensor Api KY 026, Ardino Uno

\begin{abstract}
Internet of Things (IoT) is a structure where objects are provided with an exclusive identity and the ability to move data across a network without requiring two-way directions such as human to human, source to destination or human to computer interactions. IoT allows users and devices to be connected anytime, anywhere, and with anything. The purpose of this study is to determine how the IoT implementation works or the mechanism of the Arduino Uno based automatic grill using the Thermocouple sensor and the KY 026 Fire Sensor as the input. Based on the results of the research, it shows that NodeMCU can be connected with a distance of 60 meters from the source of the network source without any objects that can obstruct the internet connection and experience a delay of under one second at a distance of 35 meters.
\end{abstract}

Keywords: Internet of Things (IoT), Thermocouple, NodeMCU, Fire Sensor KY 026, Arduino Uno

\section{PENDAHULUAN}

\subsection{Latar Belakang}

Perkembangan zaman membuat pola hidup manusia berkembang. Dimana sebelumnya manusia masih melakukan proses pemanggangan secara manual, berbeda dengan masa sekarang ini atau biasa disebut dengan era milenial yang semuanya dilakukan menggunakan teknologi digital. 
Hampir setiap orang sudah memiliki perangkat digital atau gadget yang memiliki banyak fitur untuk mempermudah pekerjaan manusia atau sekedar menghibur.

Perlu adanya pemanfaatan terhadap teknologi yang sudah semakin berkembang untuk mengurangi beban yang ditanggung dan mengurangi terjadinya risiko kesalahan yang berakibat buruk atas kelalaian yang dilakukan oleh manusia pada saat proses pemanggangan itu sendiri. Maka dari itu, perlu adanya gagasan untuk membuat sebuah alat yang dapat membantu pekerjaan manusia khususnya dalam hal memanggang tentunya dengan menggunakan perangkat digital smartphone.

Implementasi IoT pada alat pemanggang otomatis diharapkan dapat mempermudah pekerjaan manusia dalam hal efisiensi waktu dan tenaga dari segi monitoring suhu, dengan sistem kerja IoT pada pemanggang otomatis yang menggunakan ESP 8266 berbasis arduino uno. IoT memiliki kemampuan untuk memudahkan pekerjaan manusia dalam mengirim data tanpa adanya interaksi dua arah yaitu, manusia ke manusia atau manusia ke komputer. ESP 8266 bermanfaat guna mempermudah pembuatan platform untuk IoT karena memiliki fitur Wifi, sedangkan arduino uno memiliki kegunaan sebagai mikrokontroller yang berfungsi sebagai otak dalam suatu alat karena di bagian arduino adalah tempat proses pengolahan data, sehingga arduino uno berbasis ESP 8266 memiliki kegunaan untuk mengembangkan atau menciptakan teknologi karena memiliki fitur yang dapat memudahkan pekerjaan manusia. Maka implementasi IoT pada pemanggang otomatis yang menggunakan ESP 8266 berbasis arduino uno untuk memonitoring suhu dan adanya api pada alat panggangan pada saat proses pemanggangan terjadi.

\subsection{Tujuan}

Tujuan dari penelitian ini adalah untuk mengetahui peran dari modul Internet of Things sebagai monitoring suhu, untuk mengetahui cara kerja dari modul Internet of Things sebagai monitoring suhu dan dan untuk mengetahui implementasi modul Internet of Things pada pemanggang otomatis.

\subsection{Identifikasi Masalah}

Identifikasi masalah pada penelitian ini ialah proses pemanggangan yang masih banyak dilakukan secara manual, perkembangan teknologi seiring berkembangnya zaman, perlu adanya media untuk memonitoring suhu pada pemanggang otomatis dan perlunya rancangan sistem IoT pada Pemanggang otomatis agar mendukung pemanggang otomatis dalam menjalankan perannya.

\subsection{Metoda Penelitian}

Metoda yang dilakukan dalam penelitian ini adalah sebagai berikut:

1. Studi Pustaka, adalah langkah awal dalam metode pengumpulan data, merupakan metode pengumpulan data yang diarahkan kepada pencarian data dan informasi melalui sumbersumber kongkret yang mendukung penelitian.

2. Studi bimbingan adalah kegiatan yang dilakukan dengan cara berdiskusi dan berkonsultasi dengan dosen pembimbing tugas akhir mengenai penelitian yang sedang di rancang.

3. Studi lapangan adalah suatu kegiatan untuk mengamati objek yang sedang diteliti secara langsung.

\section{DASAR TEORI /MATERIAL DAN METODOLOGI/PERANCANGAN}

\subsection{Landasan Teori}

2.1.1 Arduino Uno 
Sebuah board mikrokontroller yang menggunakan IC Atmega328 memiliki 14 pin digital Input atau output (6 diantaranya dapat digunakan sebagai output PWM), 6 pin input analog, osilator, koneksi USB, power jack, dan sebuah tombol reset. Arduino uno diprogam melalui perangkat lunak atau aplikasi yang bernama Arduino IDE, Arduino IDE diprogam melalui PC dengan menggunakan bahasa progam $\mathrm{C}$ yang telah didesain untuk mempermudah user dalam menjalankan sebuah progam di arduino uno [2].

Arduino uno dapat dikatakan sebagai sebuah platform dari physical computing yang bersifat open source. Arduino uno bukan hanya sekedar alat pengembangan, namun arduino uno adalah sebuah kombinasi dari hardware, IDE (Integrated Development Evirontment), dan bahasa pemograman yang sangat canggih. Komponen utama yang digunakan arduino uno adalah sebuah chip mikrokontroller 8 bit merk ATMega yang dibuat perusahaan Atmel Corporation [1].

\subsubsection{Arduino IDE (Integrated Develpoment Envirotment)}

Merupakan lingkungan terintegrasi yang digunakan untuk melakukan pengembangan. Pada tampilan awal arduino IDE terdapat ombol verify dapat mengkompilasi progam yang ada di editor, Tombol New memiliki fungsi membuat progam baru dengan mengosongkan isi dari jendela editor. IDE memberikan kesempatan untuk menyimpan semua perubahan yang sebelumnya belum di save. Ketika mengklik tombol upload Arduino IDE mengkompilasi progam dan upload ke papan arduino uno yang telah dipilih di IDE menu Tools lalu ke serial port [3].

\subsubsection{NodeMCU}

Salah satu pengendali mikro single-board yang memiliki fungsi Wifi membuat NodeMCU berguna dalam pembuatan produk platform IoT, NodeMCU memiliki perangkat keras berupa system on chip, bersifat open source dan menggunakan script LUA sebagai bahasa progammnya. Memprogam NodeMCU tergolong sedikit sulit karena diperlukan wiring serta tambahan modul NodeMCU Wifi to serial untuk mengunduh progam [4].

\subsubsection{ESP8266}

Sebuah modul teknologi yang menggunakan peralatan elektronik untuk bertukar data secara nirkabel (menggunakan gelombang radio) melalui sebuah jaringan komputer, termasuk koneksi intertenet yang berkecepatan tinggi dan didasari pada spesifikasi IEEE. Melakukan pengaturan konfigurasi modul ESP8266 dapat dilakukan di dalam mode AT Command. AT Command sendiri memiliki fungsi untuk berkomunikasi dengan modul ESP8266 hanya melalui port pada computer [5].

\subsubsection{Blynk}

Bylnk merupakan platform aplikasi yang dapat diunduh secara gratis oleh pengguna android maupun iOS yang memiliki fungsi untuk mengontrol arduino, raspberry pi dan sejenisnya melalui jaringan internet. Blynk tidak terikat pada papan atau perisai khusus, dirancang untuk Internet of Things dengan fungsi untuk mengontrol hardware dari jarak jauh, dapat menampilkan data visual, sensor, dan hal lainnya yang canggih tentunya [5].

\subsubsection{Thermocouple}

Jenis sensor suhu yang memiliki fungsi untuk mengukur atau mendeteksi suhu melalui kedua jenis logam yang berbeda yang digabung pada ujungnya sehingga menimbulkan efek thermoelectric (sebuah logam konduktor yang diberi perbedaan panas secara gradient akan menghasilkan 
tegangan listrik). Memiliki kelebihan merespon dengan cepat terhadap suhu dan juga rentang suhu yang memiliki kisaran -2000C sampai 20000C menjadikannya pilihan yang tepat untuk mendeteksi suhu [6].

\subsubsection{Sensor Api KY 026}

Jenis sensor yang digunakan untuk mendeteksi nyala api dan bukan mendeteksi dari suhu api melalui sensor optik. Sensor api KY 026 akan bisa mendeteksi api jika ada keberadaan spektrum cahaya inframerah ataupun ultraviolet, dan mikroprosessor akan mendeteksi spektrum cahaya yang ada pada api tersebut. Karena itu, sensor akan mendeteksi inframerah atau ultra violet dari api di bagian daerah yang diproteksi atau yang ditempatkan sebelumnya [7].

\subsubsection{Internet of Things (IoT)}

Sebuah konsep di mana objek yang memiliki kemampuan untuk mengirim data melalui jaringan tanpa memerlukan adanya interaksi dari manusia ke manusia atau dari manusia ke komputer. Internet of Things (IoT) adalah struktur di mana objek, orang disediakan dengan identitas eksklusif dan kemampuan untuk pindah data melalui jaringan tanpa memerlukan dua arah antara manusia ke manusia yaitu sumber ke tujuan atau interaksi manusia ke komputer. Dengan adanya IoT memungkinkan pengguna dan perangkat dapat terhubung kapan saja, dimana saja, dan dengan apa saja. Dalam penggunaannya Internet of Things dapat dijumpai dalam kehidupan sehari-hari, diantaranya adalah Smart Parking, Industrial Control, Energy Smart Grid, Smart City, dan lain-lain [8].

\subsection{Meodelogi/Perancangan}

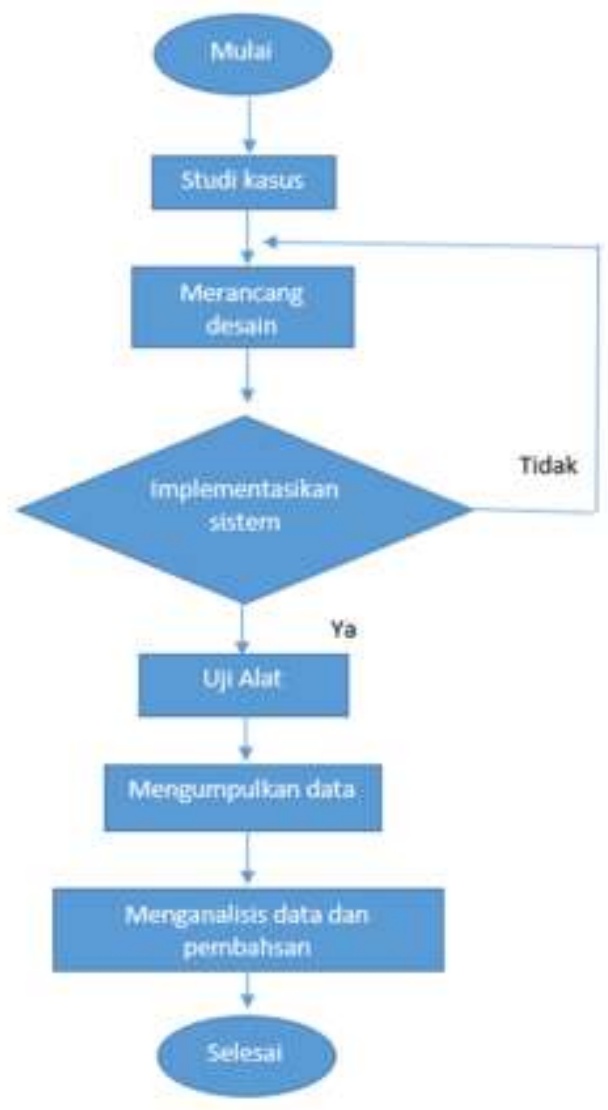

Gambar 2.1 Metodelogi Penelitian 


\subsubsection{Perancangan Hardware}

Pada perancangan hardware sistem ini akan membahas rangkaian sistem monitoring pada pemanggang otomatis. Rancangan ini memiliki fungsi untuk memenuhi spesifikasi sistem yang telah dirancang sedemikian rupa, berikut ini adalah blok diagram keseluruhan sistem monitoring berbasis IoT dalam Pemanggang otomatis:

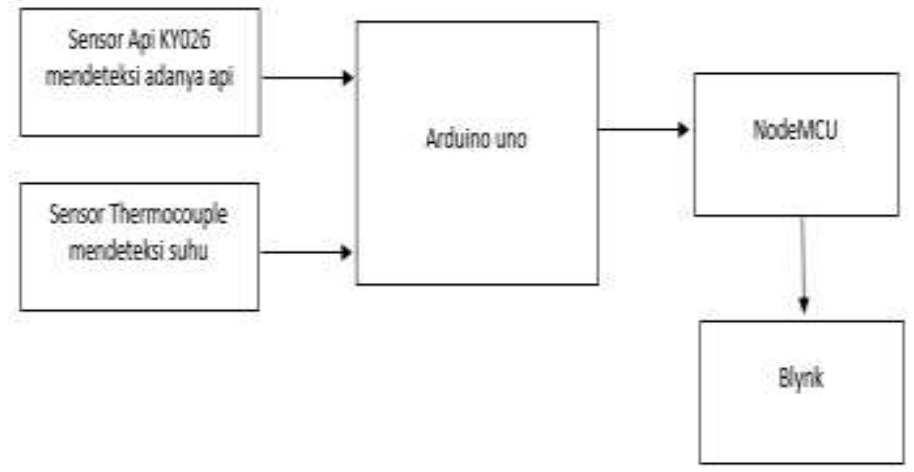

Gambar 2.2 Blok diagram Rancangan Sistem Monitoring

Dalam rancangan tersebut Sensor Api KY026 dan Sensor Thermocouple memiliki peran memberikan data atau sebagai input dalam sistem, setelah mendapatkan data dari sensor kemudian diteruskan ke bagian proses yaitu di Arduino dan NodeMCU disnilah data diolah dan akan ditampilkan hasil data di aplikasi Blynk atau yang berperan sebagai output dalam sistem ini.

\subsubsection{Sistem Monitoring}

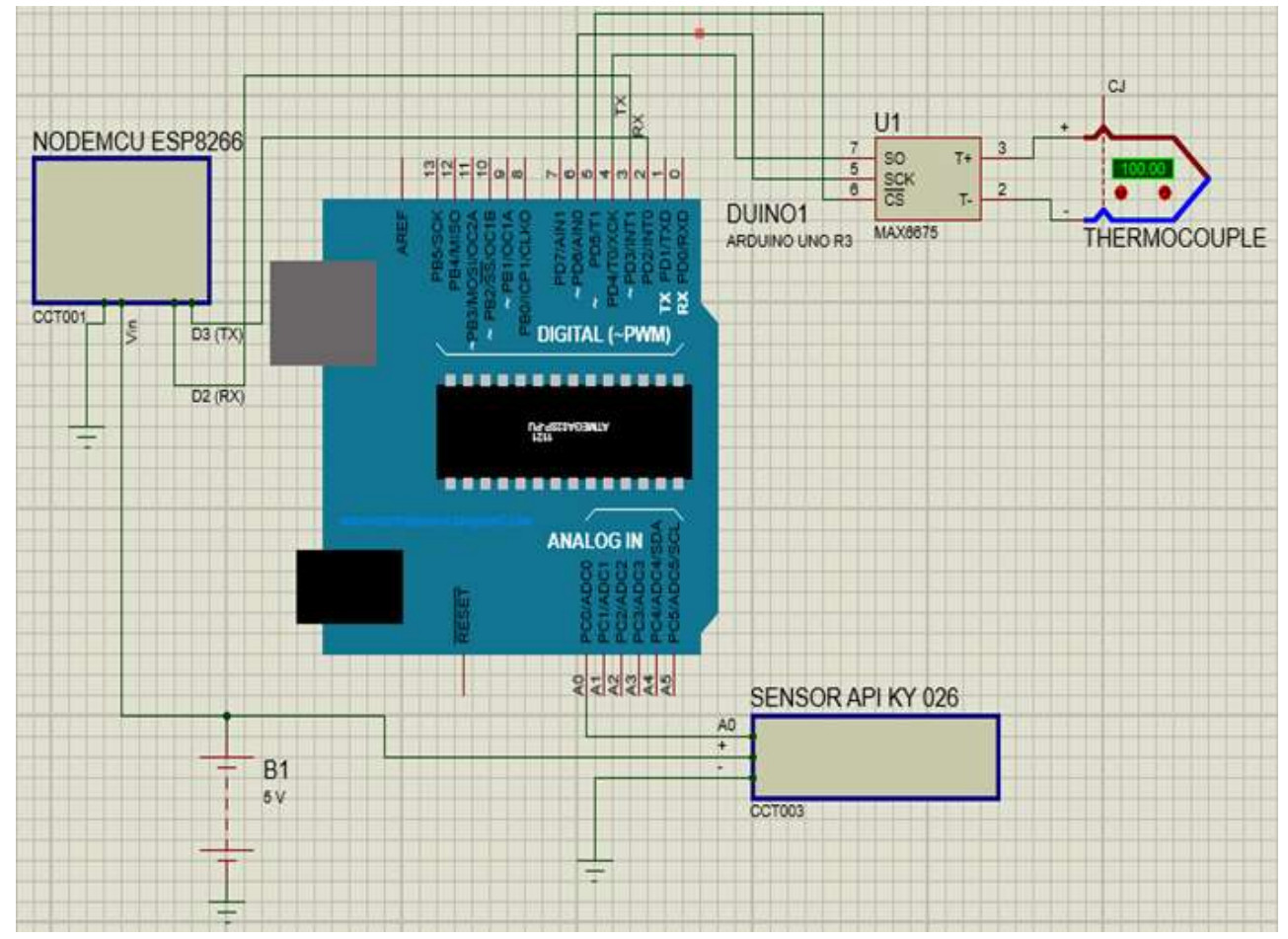

Gambar 2.3 Skematik Monitoring Berbasis IoT

Sistem ini memiliki Arduino sebagai mikrokontroller dalam sistem monitoring, Sensor Thermocouple memiliki dua kaki pin yang terhubung menjadi modul Max 6675 mempunyai 3 pin yaitu SO, CS, CSK yang terhubung masing-masing di pin 4, pin 5, pin 6 digital arduino. Sensor Api KY 026 memiliki tiga kaki pin yaitu pin positif (+), pin negatif (-), dan pin AO (Analog 
Output), untuk pin positif terhubung ke sumber $5 \mathrm{~V}$ modul LM 256 dan untuk pin negatif akan terhubung ke ground modul LM 256 sedangkan pin AO akan dihubungan ke pin A0 (Analog 0) arduino. NodeMCU memiliki 4 buah kaki pin yaitu pin D2(RX), D3(TX), VIN, Ground, Untuk pin D2 (RX) akan dihubungkan ke pin 3 digital arduino sebagai TX, pin D3 (TX) dihubungkan menjadi pin 2 digital arduino sebagai RX, Vin dihubungkan ke sumber LM256, dan ground dihubungkan ke Ground LM 256.

\subsubsection{Perancangan Software}

Dalam penggunaan sistem ini aplikasi android dimanfaatkan untuk memonitoring menggunakan dua sensor yaitu Sensor Thermocouple dan Sensor Api KY 026. Aplikasi yang dimaksud ialah aplikasi blynk yang sudah bisa di unduh di android maupun di iOS, Berikut keseluruhan sistem monitoring:

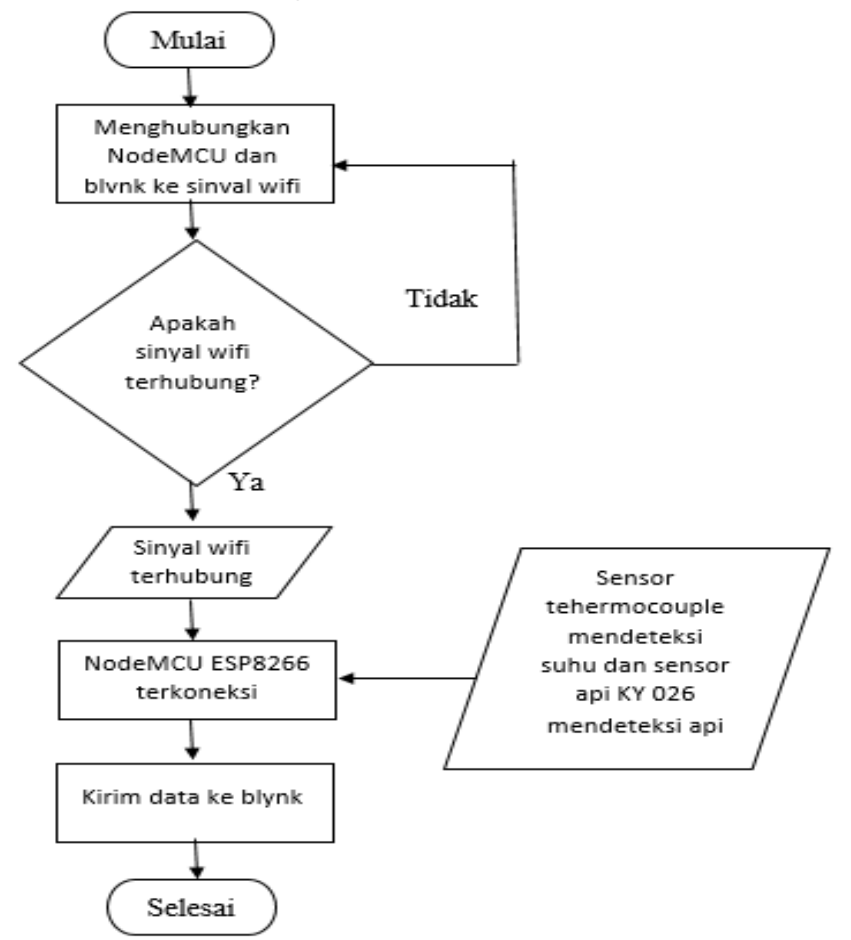

Gambar 2.4 Flowchart Keseluruhan Sistem Software

\section{PEMBAHASAN}

\subsection{Hasil Implementasi}

Memiliki tujuan untuk mengetahui apakah perancangan program pada sistem dapat melakukan pengoperasian sistem tersebut. Pada proses implementasi dibutuhkan perangkat pendukung yang memadai agar dapat membantu dalam melakukan proses implementasi. Berikut adalah perangkat lunak serta spesifikasi yang dibutuhkan pada proses implementasi software:

Tabel 3.1 Spesifikasi PC/ Komputer yang digunakan untuk implementasi

\begin{tabular}{|l|l|}
\hline \multicolumn{1}{|c|}{ NAMA } & \multicolumn{1}{c|}{ SPESIFIKASI } \\
\hline CPU & AMD A9-9420 RADEON R5, COMPUTE CORE 2C+3G 3.00GHz \\
\hline RAM & 4 GB \\
\hline STORAGE & 500GB HDD \\
\hline OS & WINDOWS 10 \\
\hline
\end{tabular}


Peneliti menggunakan PC dengan spesifikasi yang tertera pada tabel diatas untuk membantu dalam melakukan menginput data, memproses data, mengirim data yang dimplementasikan pada aplikasi Arduino IDE dan Blynk.

Tabel 3.2 Spesifikasi Smartphone yang digunakan untuk implementasi

\begin{tabular}{|l|l|}
\hline \multicolumn{1}{|c|}{ NAMA } & \multicolumn{1}{c|}{ SPESIFIKASI } \\
\hline CPU & SNAPDRAGON 665 AIE \\
\hline RAM & 4 GB \\
\hline STORAGE & 128 GB \\
\hline OS & ANDROID 10 \\
\hline
\end{tabular}

Selain PC, peneliti menggunakan smartphone android, memiliki tujuan untuk memproses pertukaran data atau memonitoring hasil nilai keluaran data yang telah diproses. Pada smartphone android aplikasi yang digunakan yaitu aplikasi Blynk.

\subsubsection{Implementasi Software}

\subsubsection{Implementasi Sistem Pengiriman data Modul ESP8266}

Pengiriman data modul ESP8266 ini aktif pada saat sistem power arduino atmega aktif. Sistem ini langsung mencoba terhubung dengan jaringan internet yang tersedia, kemudian sistem dapat mencoba terhubung dengan server blynk. Setelah terhubung dengan server, sistem ini akan mengirim data ke aplikasi blynk yang sudah dibuat sebelumnya. Berikut merupakan program arduino yang diimplementasikan pada sistem:

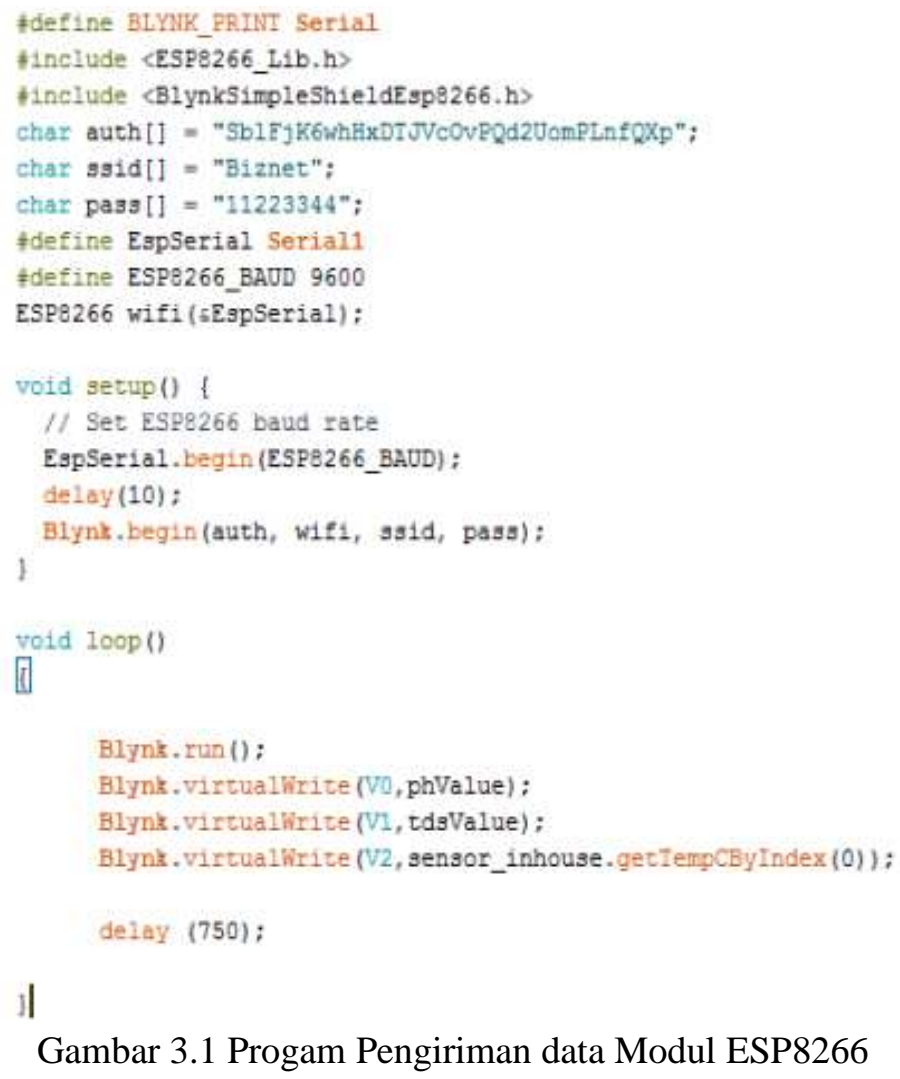

Gambar 3.1 Progam Pengiriman data Modul ESP8266

\subsubsection{Implementasi Sistem Monitoring Suhu Pada Blynk}

Pemantauan nilai sistem intrumentasi menggunakan Blynk ini secara umum menampilkan bagaimana bentuk keseluruhan software yang digunakan untuk memonitoring agar lebih mudah dan 
efesien waktu, dari software yang akan dikembangkan, Adapun pemantauannya yang menggunakan wifi agar terhubung langsung oleh jaringan koneksi internet pada smartphone yang digunakan adalah sebagai berikut:

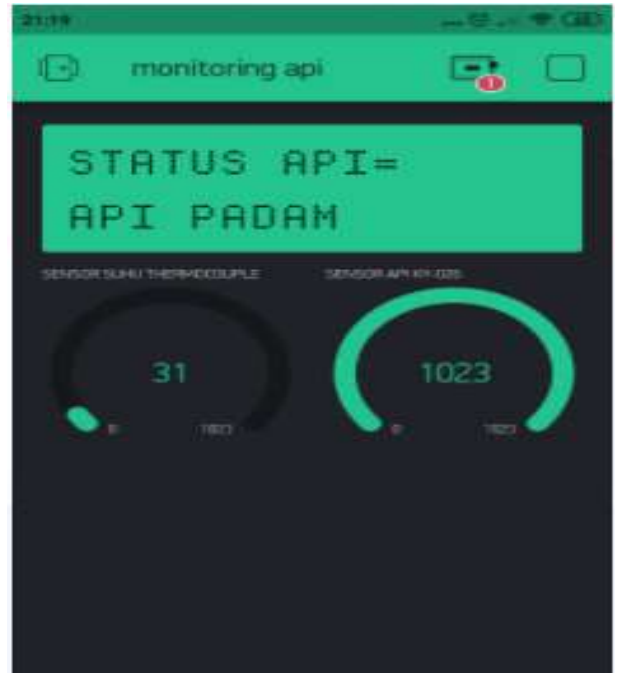

Gambar 3.2 Tampilan pada blynk

Pada aplikasi blynk akan menyajikan tampilan data keluaran nilai sensor yang dikirim arduino uno atmega melalui proses pertukaran data dari arduino atmega dengan modul ESP8266.

\subsubsection{Implementasi Hardware}

Suatu proses penerapan seluruh komponen perangkat keras pada penerapan modul ESP8266 pada sistem monitoring pemanggang otomatis berbasis Internet of Things (IoT). Beberapa hal yang perlu diperhatikan dalam proses implementasi hardware. Berikut adalah implementasi hardware yang dilakukan:

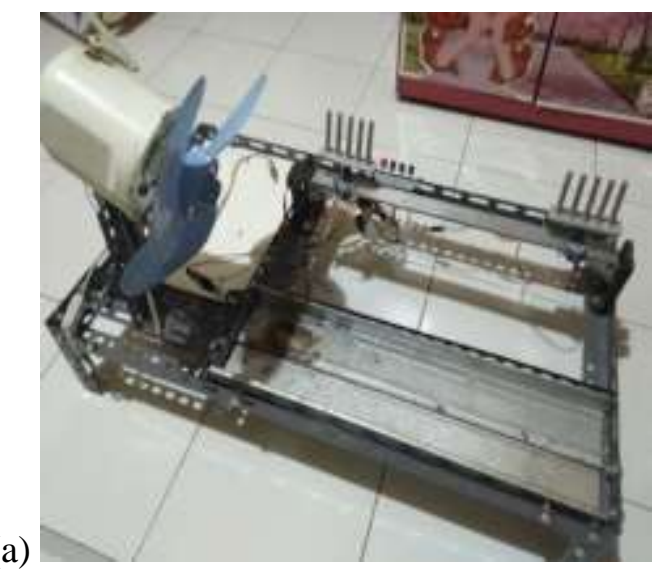

(b)

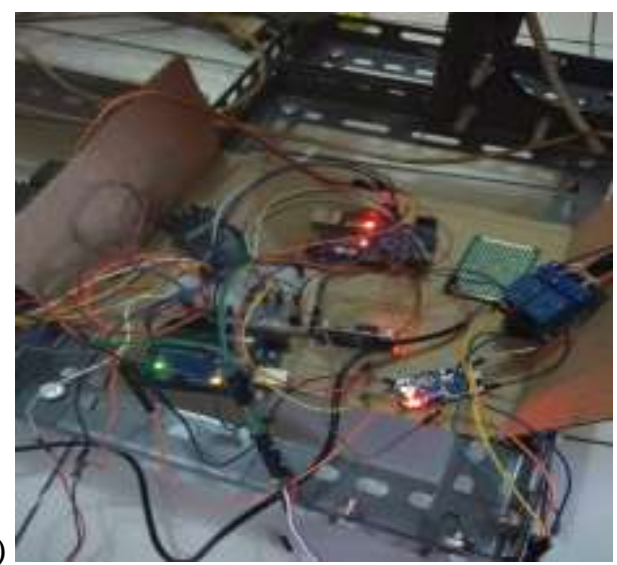

Gambar 3.3 (a) wiring pada bagian luar pemanggang. (b) wiring pada bagian dalam pemanggang.

Terlihat pada gambar (a) terdapat bagian kipas dan tombol, kipas memiliki fungsi untuk menjaga bara api agar terus menyala. Kipas langsung dihubungkan ke arduino agar langsung otomatis menyala saat power dihubungkan.

Bagian tombol memiliki fungsi untuk mereset atau memberikan perintah pada putaran motor pemanggang. Setiap tombol memiliki durasi masing-masing yang sudah di progam sebelumnya sesuai jenis daging yang ingin di panggang. Sedangkan untuk bagian dalam pemanggang memiliki beberapa peran diantaranya adalah:

1. Bagian atas 
Bagian atas terdapat komponen terminal. Komponen terminal memiliki fungsi sebagai power untuk sistem, hal ini bertujuan untuk mempermudah komponen lainnya dalam mengambil sumber tegangan yang dibutuhkan.

2. Bagian bawah

Bagian ini memiliki empat komponen yaitu, mikrokontroller arduino atmega 328, modul ESP 8266, sensor thermocouple, sensor api ky 026. Arduino dan modul ESP memiliki fungsi sebagai sistem monitoring, penghubung sistem monitoring ke jaringan internet, dan pengirim data monitoring ke aplikasi blynk. Sedangkan kedua sensor yaitu sensor thermocouple dan sensor api memiliki fungsi untuk mendeteksi suhu dan nyala api.

\subsection{Pengujian}

\subsubsection{Hasil Pengujian Monitoring Sensor Pada Aplikasi Blynk}

Pengujian ini dilakukan dengan mengamati dan membandingkan data sensor thermocouple untuk memonitoring suhu dan sensor api ky 026 untuk data monitoring nyala api pada serial monitor dengan aplikasi blynk berdasarkan jarak.

Pada pengujian pertama pada sensor, data serial monitor dilakukan pengujian sensor thermocouple dan sensor api ky 026 sebanyak 6 data dari jarak $0 \mathrm{~m}$ sampai $50 \mathrm{~m}$ dengan rentang jarak $10 \mathrm{~m}$, kemudian data monitoring suhu dan monitoring nyala api diambil untuk membandingkan data tersebut dengan aplikasi blynk. Pada pengujian pertama sensor suhu satuan data masih menggunakan satuan meter $(\mathrm{m})$ untuk jarak dan Celcius $\left({ }^{0} \mathrm{C}\right)$ untuk suhu.

Tabel 3.3 Tabel hasil pengujian pertama data sensor suhu

\begin{tabular}{|l|c|c|c|}
\hline NO & $\begin{array}{l}\text { Jarak } \\
\text { Pengujian } \\
(\mathbf{m})\end{array}$ & $\begin{array}{l}\text { Data Sensor } \\
\text { Suhu di Serial } \\
\text { Monitor }\left({ }^{\circ} \mathbf{C}\right)\end{array}$ & $\begin{array}{l}\text { Data Sensor } \\
\text { Suhu di Aplikasi } \\
\text { Bylnk }\left({ }^{\circ} \mathbf{C}\right)\end{array}$ \\
\hline 1 & 0 & 29 & 29 \\
\hline 2 & 10 & 29 & 29 \\
\hline 3 & 20 & 29 & 29 \\
\hline 4 & 30 & 29 & 29 \\
\hline 5 & 40 & 29 & 29 \\
\hline 6 & 50 & 29 & - \\
\hline
\end{tabular}

Tabel 3.1 Tabel hasil pengujian pertama data sensor api ky 026

\begin{tabular}{|l|c|c|c|}
\hline NO & $\begin{array}{l}\text { Jarak } \\
\text { Pengujian } \\
(\mathbf{m})\end{array}$ & $\begin{array}{l}\text { Data Sensor } \\
\text { Api ky 026 di } \\
\text { Serial Monitor }\end{array}$ & $\begin{array}{l}\text { Data Sensor } \\
\text { Suhu di } \\
\text { Aplikasi Bylnk }\end{array}$ \\
\hline 1 & 0 & 1023 & 1023 \\
\hline 2 & 10 & 1023 & 1023 \\
\hline 3 & 20 & 1023 & 1023 \\
\hline 4 & 30 & 1023 & 1023 \\
\hline 5 & 40 & 1023 & 1023 \\
\hline 6 & 50 & 1023 & - \\
\hline
\end{tabular}

Pada pengujian pertama pada tabel diatas dapat dilihat bahwa pada jarak 0 meter sampai 40 meter data yang terdapat pada serial monitor dengan data aplikasi blynk jika dilihat berdasarakan waktu yang sama, data yang ditampilkan oleh serial monitor dengan data yang diterima atau ditampilkan di aplikasi blynk memiliki data sensor yang sama. Pada jarak lebih dari 40 meter sinyal mengalami gangguan, dan pada jarak 50 meter jaringan tidak terjangkau oleh alat dan ada benda yang menghalangi sumber internet dengan alat, sehingga hanya menampilkan data pada serial monitor. 
Pada pengujian kedua dilakukan pengujian dengan jarak $0 \mathrm{~m}$ sampai $70 \mathrm{~m}$ dengan rentang yang sama yaitu $10 \mathrm{~m}$, pada pengujian kedua dilakukan ditempat yang sama tanpa ada halangan disekitar alat untuk mengetahui apakah jangkauan yang diterima oleh NodeMCU dapat bertambah luas, pengujian kedua hampir sama dengan pengujian pertama dimana dilakukan dengan membandingkan data monitoring suhu dan monitoring nyala api pada serial monitor dengan aplikasi blynk.

Tabel 3.2 Tabel hasil pengujian kedua data sensor suhu

\begin{tabular}{|c|c|c|c|}
\hline NO & $\begin{array}{l}\text { Jarak } \\
\text { Pengujian } \\
(\mathbf{m})\end{array}$ & $\begin{array}{l}\text { Data Sensor Suhu } \\
\text { di Serial Monitor } \\
\left({ }^{0} \mathbf{C}\right)\end{array}$ & $\begin{array}{l}\text { Data Sensor Suhu } \\
\text { di Aplikasi Bylnk } \\
\left({ }^{\circ} \mathbf{C}\right)\end{array}$ \\
\hline 1 & 0 & 29 & 29 \\
\hline 2 & 10 & 29 & 29 \\
\hline 3 & 20 & 29 & 29 \\
\hline 4 & 30 & 29 & 29 \\
\hline 5 & 40 & 29 & 29 \\
\hline 6 & 50 & 29 & 29 \\
\hline 7 & 60 & 29 & - \\
\hline 8 & 70 & 29 & \\
\hline
\end{tabular}

Tabel 3.3 Tabel hasil pengujian kedua data sensor api ky 026

\begin{tabular}{|c|c|c|c|}
\hline NO & $\begin{array}{l}\text { Jarak } \\
\text { Pengujian } \\
(\mathbf{m})\end{array}$ & $\begin{array}{l}\text { Data Sensor api } \\
\text { ky 026 } \\
\text { di Serial Monitor }\end{array}$ & $\begin{array}{l}\text { Data Sensor } \\
\text { Suhu di } \\
\text { Aplikasi Bylnk }\end{array}$ \\
\hline 1 & 0 & 1023 & 1023 \\
\hline 2 & 10 & 1023 & 1023 \\
\hline 3 & 20 & 1023 & 1023 \\
\hline 4 & 30 & 1023 & 1023 \\
\hline 5 & 40 & 1023 & 1023 \\
\hline 6 & 50 & 1023 & 1023 \\
\hline 7 & 60 & 1023 & - \\
\hline 8 & 70 & 1023 & - \\
\hline
\end{tabular}

Pada hasil pengujian kedua jarak jangkauan bertambah, pengujian pertama yaitu maksimal 40 meter dan dipengujian kedua alat dapat menjangkau sampai 60 meter. Pada jangkauan 60 meter lebih jaringan terputus dengan sumber internet. Hal ini menunjukan bahwa benda disekitar alat dapat berpengaruh dari kinerja NodeMCU.

\subsubsection{Hasil Pengujian Sistem Pengiriman Data Modul ESP8266}

Pada pengujian ini dilakukan dengan cara menghidupkan sistem monitoring pada arduino atmega dan modul ESP8266 sebagai modul internet. Pengujian ini meliputi delay, kecepatan modul ESP8266 untuk dapat terhubung pada jaringan internet dan untuk mulai mengirim data di beberapa waktu yang berbeda.

Tabel 3.4 Hasil Pengujian kecepatan modul ESP 8266 ke Jaringan Internet

\begin{tabular}{|c|c|c|c|c|}
\hline NO & Jam & Telkomsel & Indosat & $\begin{array}{c}\text { Kondisi Modul } \\
\text { Esp } \mathbf{8 2 6 6}\end{array}$ \\
\hline 1 & 00.00 WIB & 2,3 detik & 2,6 detik & Terhubung \\
\hline 2 & 08.00 WIB & 2,5 detik & 2,4 detik & Terhubung \\
\hline 3 & 10.00 WIB & 2,5 detik & 2,7 detik & Terhubung \\
\hline 4 & 13.00 WIB & 2,7 detik & 2,8 detik & Terhubung \\
\hline
\end{tabular}


Tabel 3.5 Hasil Pengujian kecepatan modul ESP 8266 dalam mengirim data.

\begin{tabular}{|c|c|c|c|c|}
\hline NO & Jam & Telkomsel & Indosat & $\begin{array}{c}\text { Kondisi Modul } \\
\text { Esp } \mathbf{8 2 6 6}\end{array}$ \\
\hline 1 & 00.00 WIB & 10,2 detik & 11,4 detik & Terkirim \\
\hline 2 & 08.00 WIB & 14,7 detik & 14,3 detik & Terkirim \\
\hline 3 & 10.00 WIB & 13,5 detik & 14,1 detik & Terkirim \\
\hline 4 & 13.00 WIB & 17,6 detik & 17,2 detik & Terkirim \\
\hline
\end{tabular}

Pada saat modul ESP8266 terhubung dengan jaringan internet, sistem tidak langsung mengirimkan data ke server blynk. Hal ini dikarenakan sistem harus dapat terhubung dengan server blynk agar dapat mengirimkan data. Dilihat dari hasil yang didapatkan pada tabel diatas, dapat dikatakan bahwa kecepatan modul ESP8266 untuk dapat terhubung dengan jaringan internet membutuhkan waktu yang berbeda. Hal ini dapat disebabkan oleh beberapa faktor, antara lain:

1. Kecepatan sumber jaringan yang tidak dalam kondisi baik, artinya kecepatan sumber jaringan sangat lambat atau sedang dalam gangguan sehingga membutuhkan waktu lebih lama untuk dapat terhubung

2. Kondisi sinyal provider atau penyedia jaringan internet yang sedang banyak digunakan dijam tertentu sehingga dapat menyebabkan gangguan pada modul ESP 8266

3. Jarak sumber jaringan yang terlalu jauh sehingga membutuhkan waktu lebih lama untuk dapat terhubung dengan jaringan internet.

Tabel 3.6 Hasil Pengujian delay modul ESP 8266

\begin{tabular}{|c|c|c|c|}
\hline NO & $\begin{array}{c}\text { Jarak Pengujian } \\
(\mathbf{m})\end{array}$ & Kondisi & Delay (s) \\
\hline 1 & 5 & Terhubung & 0,23 \\
\hline 2 & 10 & Terhubung & 0,43 \\
\hline 3 & 15 & Terhubung & 0,66 \\
\hline 4 & 20 & Terhubung & 0,76 \\
\hline 5 & 25 & Terhubung & 0,83 \\
\hline 6 & 35 & Terhubung & 0,98 \\
\hline 7 & 40 & Terhubung & 2,5 \\
\hline
\end{tabular}

Pada pengujian ini dilakukan pengujian untuk mengetahui kondisi sinyal pada aplikasi blynk berdasarkan jarak, pengujian dilakukan dalam kondisi terdapat benda yang menghalangi sinyal. Pada pengujian pertama didapat sinyal terhubung dari jarak 10 meter samapai 40 meter, pada jarak 10 meter sampai jarak 35 meter delay yang diterima dibawah 1 detik sehingga bisa dikatakan normal, namun pada jarak 40 meter sinyal mengalami gangguan karena banyak halangan yang mempengaruhi sinyal sehingga data yang diterima mencapai delay sampai 2,5 detik.

\section{KESIMPULAN}

\subsection{Kesimpulan}

Implementasi Internet of Things (IoT) pada alat pemanggang otomatis mempunyai beberapa kesimpulan, diantaranya ialah:

1. Pada jam 00.00 WIB NodeMCU dapat terhubung dengan kecepatan maksimal dikarenakan jaringan sedang tidak banyak digunakan.

2. NodeMCU dapat digunakan dengan baik sehingga dalam kondisi jarak 60 meter dapat terhubung dengan sumber internet. 
3. Dari hasil pengujian sistem pengiriman data modul ESP 8266 modul bekerja sangat baik dengan rata rata delay dibawah satu detik.

4. Berdasarkan penelitian provider Telkomsel lebih unggul dibandingkan Indosat dalam penyediaan jaringan internet.

\subsection{Saran}

Penelitian ini perlu adanya kajian lebih lanjut agar dapat mengembangkan penelitian ini ke tahapan yang lebih baik lagi.Saran yang terdapat dalam penelitian ini ialah sebagai berikut:

1. Perlu adanya pengembangan di bagian body alat agarterlihat lebih baik dan kuat di segala medan.

2. Perlunya ditambahkan penguat sinyal agar jangkauan internet yang diterima oleh NodeMCU semakin luas.

\section{DAFTAR PUSTAKA}

[1] Djuandi, F. (2011). Pengenalan arduino. E-book. www. tobuku, 1-24.

[2] Kadir, A. 2015. Panduan Praktis Memperlajari Aplikasi Mikrokontroler dan Pemrogramnanya Menggunakan Arduino. Penerbit Andi. Yogyakarta

[3] Pratama, A. (2017). Rancang Bangun Background Electric Portable Berbasis Arduino Uno dengan Kendali Smartphone Android (Doctoral dissertation, Politeknik Negeri Sriwijaya).

[4] Nurlianisa, F. R. (2018). Kit Aquascape Berbasis Internet of Things melalui Aplikasi Blynk dengan Arduino Uno untuk Pemeliharaan Lilaeopsis Brasiliensis

[5] H. Yuliansyah, "Uji Kinerja Pengiriman Data Secara Wireless Menggunakan Modul ESP8266 Berbasis Rest Architecture” Intitut Teknologi Sumatra, Juli 2016

[6] Sentosa Adrie (2016). Rancang Bangun kendali jarak jauh robot servis pembersih debu berbasis Internet of Things. Fakultas Teknologi Elektro. Institut Teknologi Sepuluh Nopember.Surabaya

[7] Yudhanto, Adiguna (2020). Implementasi Sensor Thermocouple Berbasis Telemetri Untuk Mengukur Thermal Pembakaran Propelan Roket. Jurnal Aplikasi Sains, Informasi, Elektronika dan Komputer.

[8] Humaira, Annisa, \& Rasyid. (2017). Rancang Bangun Robot Cerdas Pemadam Api Beroda dengan Pemantauan Berbasis Wifi. Universitas Andalas.

[9] Supriyade, S., Listiyoko, L., \& Fahrudin, A. (2020). Sistem Pendeteksi Ketinggian Air Menggunakan Internet Of Things Berbasis Android Untuk Memberikan Informasi Data Ketinggian Air Melalui Notifikasi Email. Jurnal Komputer dan Informatika, 15(1), 260-273. 